\title{
DIMENSÕES SÓCIO-HISTÓRICAS DA REFORMA DO ENSINO MÉDIO (LEI 13415/2017): A EDUCAÇÃO PARA O TRABALHO NO CONTEXTO DAS POLÍTICAS DE FINANCIAMENTO EDUCACIONAL
}

\author{
João Paulo Pereira Coelho ${ }^{1}$, Paulo Rogério de Souza ${ }^{2}$ \\ ${ }^{1}$ Doutor em Educação pela Universidade Estadual de Maringá - UEM. Professor da área de Políticas Públicas da \\ Universidade Estadual de Maringá - UEM, Maringá, PR. E-mail: joaoppc22@hotmail.com \\ ${ }^{2}$ Doutor em Educação pela Universidade Estadual de Maringá - UEM. Professor da área de Políticas Públicas da \\ Universidade Estadual de Maringá - UEM, Maringá, SP. E-mail: paulolucka@gmail.com
}

\section{RESUMO}

O trabalho analisa a reforma do Ensino Médio (Lei 13415/2017) a partir da dinâmica histórica das políticas educacionais voltadas a este nível de ensino. Tratando-se de uma pesquisa de caráter bibliográfico e documental, procurou-se problematizar a Lei 13415/2017 a partir das contradições sociais e políticas que permeiam a relação entre educação secundária e trabalho no Brasil. Historicamente, a ampliação do acesso à educação pública em nível médio constitui-se como um projeto em favor da qualificação para o trabalho urbano industrial, mobilizado por setores econômicos hegemônicos, e sob a orientação e financiamento de organizações internacionais. Neste processo, a nova lei do Ensino Médio significa uma reorganização das políticas educacionais voltadas à formação para o trabalho que emergem ciclicamente no Brasil, particularmente em contextos de dissolução da democracia.

Palavras-chave: Lei 13415/2017. Ensino Médio. Financiamento Educacional. Educação para o trabalho.

\section{HISTORICAL DIMENSIONS OF THE HIGH SCHOOL REFORM (LEI 13415/2017): TRAINING FOR WORK IN THE CONTEXT OF EDUCATIONAL FINANCING POLICY}

\begin{abstract}
This paper analyzes the High School Reform (law 13415/2017) from the historical dynamics of educational policies aimed at this level of education. As a bibliographical and documentary research, we goaled to problematize the law 13415/2107 from the social and political contradictions that permeate the relation between secondary education and work in Brazil. Historically, the expansion of access to public education at the middle level has constituted a project in favor of qualification for industrial urban work, mobilized by hegemonic economic sectors, and under the guidance and funding of international organizations. In this process, the new law of the Secondary School means a reconfiguration of the educational policies geared towards the formation of work that cyclically emerge with more vigor in Brazil, particularly in contexts of dissolution of democracy

Keywords: Law 13415/2017. High school. Educational Funding. Education for work.
\end{abstract}

\section{INTRODUÇÃO}

As políticas educacionais voltadas para o Ensino Médio articulam-se com a constituição histórica e econômica da sociedade brasileira. Neste âmbito, emerge ciclicamente um ponto culminante a respeito das exceptivas sociais e econômicas que este nível de ensino deve suprir: O Ensino Médio deve voltar-se a uma formação propedêutica, para que, assim, garanta a todo egresso a possibilidade de realizar um curso superior, ou voltar-se para a formação para o trabalho de forma distanciada de uma formação humanista?

Entende-se que esta dualidade está na gênese do processo de ampliação do acesso ao nível secundário, em particular, em contextos em que toma forma projetos de nação com pretensões urbanas e industriais. Neste aspecto, a Lei $13415 / 2017$, como um ponto culminante destas expectativas acerca da formação em nível médio, articula-se com reflexões mais amplas, 
que remetem as origens do ensino secundário no Brasil.

Entende-se que a concepção de que o ensino em nível médio como expressão de uma articulação entre educação e trabalho emerge, no Brasil, a partir do processo de internacionalização da economia do país, iniciada no contexto da década de 1970. A busca por tornar o país mais atrativo às grandes empresas internacionais favoreceu para que fossem implementadas, pela educação, formas mais sofisticadas no processo de organização do trabalho - um projeto que toma forma em um contexto de dissolução dos valores democráticos e subordinação a organismos internacionais que, guardadas a devidas distinções temporais, em certo nível, se assemelha ao contexto de elaboração da Lei $13415 / 2017$.

\section{METODOLOGIA}

O presente trabalho tem caráter bibliográfico, tratando-se de uma pesquisa conceitual baseada em análise de fontes documentais primárias e literatura de apoio. Os procedimentos a serem realizados, uma vez concluída a seleção da literatura, foram uma leitura pormenorizada e a análise dos textos para contextualização histórica e política do objeto, como também a sua leitura crítica.

Para se analisar as formulações que a Lei 13415/2017 estabelece para a formação do sujeito e a sua relação com a sociedade, é necessário, antes, uma compreensão sóciohistórica das políticas educacionais que estão postas no seio da sociedade brasileira; conhecer as determinações sociais, políticas e econômicas envolvidas na constituição do objeto a ser estudado. Ou seja, faz-se necessário considerar que a sociedade brasileira passou por um período de mudanças econômicas que trouxeram novas necessidades ao sistema produtivo. Nesse processo foram aproveitados e adaptados princípios pedagógicos que coadunam com esse novo momento da sociedade.

Essa busca pela compreensão da macroestrutura da sociedade brasileira se deu devido à compreensão de que, anteriormente ao fato de a educação tomar contornos "institucionais", ela é constituída a partir dos anseios e necessidades da sociedade de cada época. Nesse processo, é na materialidade da vida dos homens, em seu convívio em sociedade, que são maturadas as ideias educacionais que, por fim, tomam corpo na forma de lei, para serem aplicadas na escola em seu viés institucionalizado.

\section{Políticas para a educação secundária em suas dimensões históricas.}

Considerando que as primeiras iniciativas para a criação de escolas secundárias ${ }^{1}$, no Brasil, remontam à época colonial, historicamente, este nível de ensino se desenvolveu sob a tutela financeira e pedagógica da iniciativa dos jesuítas. Desde a chegada dos jesuítas no Brasil (1549) até a sua expulsão (1759), as preocupações com a formação em nível secundário partiu da livre iniciativa da Igreja, tanto no âmbito da decisão sobre as regiões em que os colégios secundários seriam implantados, como na esfera dos investimentos necessários à infraestrutura. Eram colégios voltados a formação de jovens pertencentes a camadas abastadas; estudantes que residiam principalmente em cidades que ganhavam relevo na composição do que viria a ser a sociedade brasileira (Rio de Janeiro, Olinda, Espírito Santo, São Luís, Ilhéus, Recife, Santos, Porto Seguro, Paranaguá).

No decorrer de pouco mais de dois séculos da permanência dos jesuítas foram criados 18 estabelecimentos de ensino secundário, voltados à formação dos quadros da Igreja e de jovens que, futuramente, iriam para Portugal dedicarem-se à formação superior. Uma primeira iniciativa que, em certo nível, pode ser considerado um esboço de uma política pública para o ensino secundário serão as aulas régias. Em 28 de junho de 1759, D. José I, assina o documento conhecido como Alvará e Instruções em que extingue todas as escolas reguladas pelo método jesuítico, instituindo um novo regime educacional que contemplava as humanidades (latim, grego e retórica) (ANDRADE, 1984).

Já no âmbito do financiamento do ensino secundário, diante da urgente necessidade de contratação de professores para atuar neste nível de ensino, é instituído o tributo denominado como Subsídio Literário, que incidia sobre a carne e a água ardente. Conforme definido em Carta Régia redigida em 1772, será destinada a

\footnotetext{
${ }^{1}$ Historicamente, o nível de escolarização voltada àqueles jovens que tinham a expectativa de frequentarem a um curso superior recebeu nomenclaturas distintas. O referido nível de ensino já foi chamado de curso médio, ensino secundário e ginasial. (Reforma Benjamin Constant - 1890; Reforma Epitácio Pessoa - 1901; Reforma Maximiliano - 1915). O conceito de ensino secundário como a educação destinada dos 15 aos 17 anos prevalece no contexto colonial, bem como a partir de 1925, com a Reforma Rocha Vaz.
} 
educação: "de um real em cada arratel [arratel = $429 \mathrm{~g}]$ de carne que se cortar no açougue; de dez réis em cada canada [2.622 litros] de aguardente das que se fazem nas terras" (ALMEIDA apud PINTO, 2000, p.8).

Em um primeiro momento, esta fonte de financiamento possibilitou a contratação de professores e, por extensão, a diversificação das aulas oferecidas aos alunos no nível secundário (CARVALHO, 1996). Todavia, em meados do século XIX, devido às recorrentes fraudes por parte dos comerciantes para não pagarem 0 tributo, há uma diminuição crescente da remuneração dos professores. Na década de 1810, das arrecadações feitas pela coroa, não era possível que fossem remunerados, mesmo que precariamente, mais do que trinta professores no Rio de Janeiro - então, capital da colônia (ALMEIDA, 1989).

A constituição do Império, em 1822, e a tomada de relativa autonomia política e financeira por parte do nascente Estado brasileiro, não significou maiores responsabilidades por parte da união no que se refere à educação pública. Com a promulgação do Ato Adicional de 1834, o ensino das primeiras letras e o ensino secundário passou a ser responsabilidade das províncias, cabendo às assembleias provinciais dar providências sobre a "instrucção publica e estabelecimentos proprios a promove-la, não comprehendendo as faculdades de Medicina, os Cursos Juridicos, Academias actualmente existentes [...]" (BRASIL, 1834, Art. $10 \S 2$ ㅇ).

O referido Ato Adicional, de 1834, no âmbito das origens históricas das políticas educacionais, foi um marco quanto à discussão a respeito do processo de centralização e descentralização pelo qual a educação brasileira passa ciclicamente. É neste contexto que emergem questões que ainda são atuais: Qual a responsabilidade e expectativas de cada instância governamental quanto à organização e o financiamento da instrução pública em nível secundário? De fato, "[...] chamou-se a esse Ato Adicional de 1834 de descentralizador, quando, na realidade, pelo menos em educação, só descentralizava algo que não se considerava suficientemente importante (TEIXEIRA, 1999, p. 357). Todavia, em um país que a maioria da população carecia, a princípio, de educação básica, o governo central passou a ter como responsabilidade o ensino superior.
Há que se considerar que foi apenas a partir da instituição da República (1889) que, com - aprofundamento dos debates acerca da necessidade de direcionar maiores recursos à educação, ocorrerá, de fato, investimentos mais concretos no ensino secundário. Na constituição de 1934 é estabelecido que "[...] a União e os Municípios aplicarão nunca menos de dez por cento, e os Estados e o Distrito Federal nunca menos de vinte por cento, da renda resultante dos impostos na manutenção e no desenvolvimento dos sistemas educativos" (BRASIL, 1934, Art. 156). Todavia, historicamente, o estado, como um espaço de lutas sociais, e que tendem a favorecer setores hegemônicos da sociedade, expressa as tensões sobre qual projeto de nação se queria implementar na primeira metade do século XX. Neste aspecto, ao nos voltarmos a questão da vinculação orçamentária, ela foi objeto dessas disputas, sendo retirada da Constituição de 1937.

A vinculação orçamentária voltaria a Constituição em 1946, em um contexto em que a retomada dos valores democráticos favoreceu as deliberações políticas a este favor. Neste contexto, ao mesmo tempo em que o ensino secundário começa a ser esboçado, a Reforma Capanema, instituída no contexto ditatorial de Getúlio Vargas, já havia delimitado qual era o papel do ensino secundário industrial e comercial: melhoria da mão de obra do trabalhador urbano. Assim, o secundário nas referidas áreas não poderiam ser usados como base para o ingresso no Ensino Superior - uma dicotomia que só seria superada com a Lei no 4.024/1961, que estabeleceu a equivalência entre os distintos ramos do ensino comercial e industrial.

Em síntese, o contexto do século $\mathrm{XX}$, em particular a partir dos anos de 1930, ainda que precariamente e timidamente, principia-se a ampliação da oferta de vagas no ensino secundário público, no Brasil. Neste período, são instalados os primeiros ginásios estaduais que se constituíam, naquele momento histórico, a primeira etapa do ensino secundário. Usando como locus de referência o estado de São Paulo, observa-se que, desde a década de 1940, o estado ampliou a sua rede de ginásios estaduais de 41 para 561 estabelecimentos nos anos de 1960 (BEISIEGEL, 1974). Neste âmbito, estes esforços empreendidos neste nível de ensino, primeiramente, foram entendidos como base para se principiar a projetar mais detidamente 
segundo ciclo do ensino secundário, oferecido aos adolescentes de 15 até 17 anos.

Todavia, em um contexto em que o ensino obrigatório correspondia às primeiras letras - o que, na atualidade, corresponde ao primeiro ciclo do ensino fundamental objetivamente, mobilizar recursos públicos para a ampliação do ensino secundário com um currículo humanista apresentava-se como um projeto distante da realidade educacional brasileira. No contexto da década de 1960, o que prevalecia no âmbito das expectativas referentes ao ensino secundário de formação geral, era que fosse de acesso àqueles cujas expectativas educativas superassem a necessidade de subsistência.

Esta configuração quanto ao acesso ao segundo ciclo do ensino secundário sofre transformações na década de 1970, durante o regime militar. A Lei 5.692, de 1971, promoveu uma profunda mudança na legislação educacional, que havia tomado forma na LDB 4024/61. Diante da ampla exortação do novo regime sobre a necessidade de uma educação coerente com o que seria um "projeto nacional", o regime primário e o ginásio passaram a configurarem-se como primeiro grau obrigatório; já a educação secundária passou a ser denominado como segundo grau (BRASIL, 1971, Art. $1 .^{\circ}$, cap. I).

No contexto da década de 1970, a concepção de ensino secundário e preparação básica para o trabalho confundem-se. Diante do empenho dos militares em consolidar um projeto de nação industrial, as expectativas sobre o segundo grau ganha relevo, ainda que este período seja marcado por baixos investimentos na educação pública.

Há que se considerar que foi a partir década de 1970 que ocorre, objetivamente, uma ampliação significativa das vagas no segundo grau. Entre 1971 até 1980, as vagas na rede pública subiram de 632 mil para 1.508 .000 milhões de alunos (BRASIL, 2010). Esta ampliação da oferta de vagas, ainda que substancial, inserese no contexto de implementação de ajustes estruturais empreendidos pelo Brasil, a partir da década de 1970.

No decorrer dos anos de 1970, a recessão econômica mundial fez diminuir os ânimos que predominaram durante o período pós-guerra. Tomando espaço entre as nações capitalistas, um discurso pregava a diminuição das expectativas quanto ao crescimento econômico e reorganização da economia e do estado. A crise, para Harvey (2011), começou a se aprofundar no período de 1965 a 1973, momento em que se difundem regimes e contratos de trabalho mais flexíveis. "Além do desemprego estrutural, há uma redução do emprego regular e um aumento do trabalho em tempo parcial e temporário, assim como o subcontrato" (PERONI, 2003, p. 23)

Portanto, os investimentos para a ampliação do acesso ao segundo grau estavam subordinados as condicionalidades de caráter macroeconômico, na perspectiva de manter reformas estruturais impostas pela economia global à administração pública brasileira. Assim, as vagas aumentaram significativamente, mas de forma precarizada, devido aos baixos investimentos públicos na educação pública durante o regime militar.

Nessa conjuntura, na perspectiva das agências internacionais, o Brasil passou por significativas transformações econômicas, entretanto, não se desenvolveu nesses países um projeto econômico onde pudessem caminhar para autossuficiência e o desenvolvimento efetivo da sociedade. Os planos para o desenvolvimento foram permeados pela maciça influência das agências internacionais. Da década de 1950 a 1985, os países da América Latina e Caribe receberam mais empréstimos do Banco Mundial que qualquer outra área geográfica (BACHA, 1986).

Cumprindo as expectativas das agências internacionais, os anos de 1970, no Brasil, foram marcados pela pedagogia tecnicista, cuja base é a potencialização das habilidades do sujeito para o trabalho. Neste aspecto, distanciando-se de valores pedagógicos críticos e humanistas, a educação no segundo grau consolidou-se como um projeto de formação de uma sociedade urbana industrial que suprisse as necessidades de mão de obra no contexto do "milagre econômico".

Em síntese, as lutas sociais produzidas no decorrer do século $\mathrm{XX}$, foram marcadas pela expectativa de que educação em nível médio se estabelecesse como um nível de formação em favor da luta contra exclusão e pela promoção integral do sujeito. A Constituição Federal de 1988, bem como a LDB 9394/96, embora tenham sido elaboradas a partir deste contexto de disputa com o poder econômico hegemônico, expressam anseios legítimos da sociedade. Todavia, o que se observa é que a ampliação do acesso em nível médio, historicamente, 
constituiu-se como um espaço de constante disputa pelos setores hegemônicos no sentido a urgência de se direcionar este nível de ensino para a formação para o trabalho - o que toma forma na Lei 13415/2017; reiterando uma relação linear entre escolarização e empresa, subordinando o ensino a uma concepção de produto que tem bases nas origens históricas do ensino público secundário brasileiro.

\section{A Lei 13415/2017: a educação no atual contexto de reestruturação produtiva do trabalho}

A pretensa necessidade de mudanças urgentes quanto ao currículo e organização do Ensino Médio, que tomou forma na Medida Provisória 746/2016 e posteriormente foi aprovada pelo Senado como Lei (13.415/2017), alinha-se às demandas do setor produtivo que, historicamente, emergem com maior vigor em contextos de dissolução política. Dessa perspectiva, a referida lei não é propriamente uma inovação, mas sim uma readequação da disputa pela hegemonia sobre o Ensino Médio.

Exprimindo reformulações do recorrente modelo de formação para o trabalho que historicamente se desenvolveu no Brasil, a Lei 13.415/2017 estabelece padrões de eficiência à educação que coadunam com o processo de implementação da lógica econômica neoliberal em vigência; que ganha vitalidade nesta região em meados da década de 1990, em circunstâncias nas quais o capitalismo busca se recompor a partir da superação do sistema de produção fordista/taylorista (RAMOS, 2004).

Uma dinâmica adaptativa que, a princípio, no contexto da Lei 13415/2017, instituiu-se sobre o profissional da educação: "IV - profissionais com notório saber reconhecido pelos respectivos sistemas de ensino, para ministrar conteúdos de áreas afins à sua formação ou experiência profissional" (BRASIL, 2017). O que se observa nestas determinações é a configuração de modelos de sociabilidade que favoreçam a integração do sujeito aos padrões de acumulação em tempos "pós-fordista" (RAMOS, 2004).

O caráter polissêmico do conceito de notório saber reproduzido no referido documento, age em favor da dinâmica de constantes reformulações pelas quais os modelos de organização do trabalho têm passado. Nesse contexto, tem se promovido um processo de desmantelamento das tessituras sócio-históricas imanentes ao trabalho que estimulam a competitividade e adaptação do sujeito frente às constantes transformações no sistema produtivo. Cabendo a educação a tarefa de fomentar no indivíduo a disposição para realizar por si mesmo as adequações necessárias a sua formação diante das constantes performances exigidas pelo mundo do trabalho.

O conceito de notório saber, constituído a partir das imbricações entre mobilização de conhecimentos e adaptação às inquietações socioeconômicas práticas, presentes na realidade do sujeito, vão ao encontro da formação de indivíduos com capacidades que se estabeleçam, em certo nível, para além das habilidades manuais primárias; com perspicácia para "[...] agir eficazmente em um determinado tipo de situação, apoiada em conhecimentos, mas sem limitar-se a eles" (PERRENOUD, 1999, p. 32).

Mas, uma vez que se fomentam constantes performances adaptativas à realidade amórfica do sistema produtivo, produzem-se relações de trabalho superficiais, desconectados de sua historicidade. Estas funções adaptativas para a realidade trabalho é reiterada diante de uma clara separação entre cultura e tecnologia que permeiam os eixos, uma vez que as ciências humanas aparecem deslocadas da categoria tecnologia, como se mudanças tecnológicas, por si só, operassem uma ruptura com a cultura.

Art. 35-A. A Base Nacional
Comum Curricular definirá
direitos e objetivos de
aprendizagem do ensino
médio, conforme
diretrizes do Conselho
Nacional de Educação, nas
seguintes áreas do
conhecimento:
I - linguagens e suas
tecnologias;
II - matemática e suas
tecnologias;
III - ciências da natureza e
suas tecnologias;
IV - ciências humanas e
sociais aplicadas (BRASIL,
2016).

Os eixos formativos apresentam delimitações conceituais que caracterizam a realização humana pelo exercício do trabalho de maneira separa da identificação do sujeito com as ações e interesses da coletividade. Nessa complexa dinâmica, o desenvolvimento torna-se 
sustentável por meio da constante capacitação técnica do sujeito, na qual o trabalho, a partir de uma constante formação/adaptação profissional, não só torna-se agente de transformação pessoal, mas também de seu entorno. No momento em que a educação tomar sua verdadeira função - formar indivíduos com aptidões técnicas necessárias ao modelo de produção capitalista - será consolidado o caminho para a inserção do Brasil na economia global.

Todavia, estas concepções que permeiam as mudanças no Ensino Médio representam uma tentativa de suplantar as determinações sociais e as relações de dominação que se constituem no atual modelo de produção, pois sendo cada indivíduo capaz de adquirir um "capital" inalienável - a técnica - dessa maneira, depende dele, não dos fatores econômicos, construir o seu espaço nas relações de trocas do mundo capitalista.

Observa-se que esse é um período em que o processo de concentração do capital desencadeia "uma crescente incorporação do progresso técnico da produção - arma de competição intercapitalista - e uma consequente desqualificação do trabalho" (FRIGOTTO, 2006, p. 20). Ante essa contradição, percebe-se que, ao fundamentar-se em uma perspectiva positivista para o entendimento das relações sociais, entendendo a sociedade capitalista como dada, um produto natural, a concepção de tecnologia presente na Lei 13415/2017 constitui-se como um valor "a-histórico".

Estas cisões impossibilitam a formação de um trabalhador orgânico, agentes de uma perspectiva de mudança a serem forjadas por meio das lutas desenvolvidas no seio do processo produtivo. Dissolvendo sua identidade coletiva se estabelece não só a ruptura com o exercício do trabalho enquanto processo de objetivação da cultura (DUARTE, 2003), mas também, por extensão, a ruptura com os meios pelo qual o homem poderia ser confrontado com a sua condição sócio-histórica.

Estas questões aparecem nas falas do atual ministro da Educação, Mendonça Filho, em suas coletivas em defesa das mudanças no Ensino Médio. Segundo o ministro, vive-se um momento no qual a economia brasileira alcançou um nível de desenvolvimento econômico considerável; todavia, a educação em nível médio não teria conseguido desenvolver-se na mesma intensidade que o progresso material, pois não é capaz de instrumentalizar os jovens para as demandas atuais da sociedade - o que seria o fator gerador de um alto índice de evasão entre os jovens no nível médio.

Em outros termos, a raiz das desigualdades sociais está na formação educacional, que por não ter preocupação modernizadora não capacita os indivíduos com as devidas competências exigidas pelo mundo do trabalho, o que é contemplado de forma direta na Lei 13415/2017. "I - a inclusão de vivências práticas de trabalho no setor produtivo ou em ambientes de simulação, estabelecendo parcerias e fazendo uso, quando aplicável, de instrumentos estabelecidos pela legislação sobre aprendizagem profissional" (BRASIL, 2017, Art. 36, § 6).

Ao estabelecer esta articulação entre o setor produtivo e escola, busca-se também retirar a primazia do Estado no financiamento da educação; uma política que cada vez mais distancia a educação de seus princípios norteadores - um direito de todos, conforme estabelece a Constituição Federal de 1988 e a LDB 9394/96 - para constituir-se como uma prestação de serviços. Desenvolve-se, portanto, uma relação recíproca entre educação e mercado, escola e empresa, aprendizagem e produto (FRIGOTTO, 2006).

Neste âmbito, o Banco Mundial se apresenta como um mediador/ financiador do projeto de crescimento econômico que deve ser desenvolvido no Brasil, pautado pela inserção da educação às demandas mercado. Dessa forma, o capital, tanto produtivo como humano, deve se fortalecer para a disputa na economia globalizada. Todavia, à medida que o capitalismo se desenvolve, cada vez mais os recursos necessários para a efetivação desse ideário, como o pleno desenvolvimento da ciência e da tecnologia, tornam-se mais concentrados nos países desenvolvidos.

A ideia de tecnologia que permeia as diretrizes para a educação na América Latina restringe-se a operação da produção e não ao progresso técnico nas formas de produzir (BANCO MUNDIAL, 1995). O Brasil, que, historicamente, cumpriu o papel de nações agrícolas, colocaria à disposição do mercado produtos primários, mas produzidos por meio de processos mais eficientes devido ao uso de instrumentos mais aprimorados. Por outro lado, importaria estas tecnologias necessárias para implementar o trabalho. Portanto, os indivíduos devem qualificar-se para as funções possíveis em 
sua realidade econômica e social. A educação, nesse viés, deve investir na formação de pessoas com capacidades úteis à realidade de cada país; logo, às nações pouco desenvolvidas para produzir tecnologias, cabe focar em uma formação técnica para fins práticos.

Historicamente, as agências internacionais de financiamento tomaram uma função estratégica em governos frágeis, sem legitimidade, como o vivido no contexto atual. $\mathrm{O}$ Banco Mundial, logo após a sua fundação, em 1944, inicialmente, tomou a função de auxiliar na reconstrução das nações devastadas pelas guerras. Contudo, isso não se entendeu por muito tempo. A partir das tensões cada vez mais acirradas em todo mundo, a década de 1970 foi marcada pela reorganização das políticas de investimento da agência. Promoveu-se um aumento significativo de investimentos nos países subdesenvolvidos, com enfoque, particularmente nos anos de 1990, na capacitação para o trabalho em uma condição de subordinada às economias desenvolvidas.

Ainda que os desdobramentos destas políticas de subordinação da década de 1990 permaneçam em vigência, no ano de 2017, este processo ganha maiores contornos com a Emenda Constitucional 95, que significou o desmantelamento do estado brasileiro quanto as suas responsabilidades referentes às garantias de direitos universais. Ao congelar os investimentos públicos por 20 anos - exceto aqueles valores destinados ao pagamento de juros e amortizações da dívida pública -, a ideia de urgência de parcerias público privado, bem como a necessidade de financiamento de grandes organismos internacionais, é legitimada.

É a partir deste contexto que o Ministério da Educação foi autorizado a iniciar negociações de empréstimos na ordem de US\$ 250 milhões junto ao Banco Internacional para a Reconstrução e Desenvolvimento para implementar as mudanças que tomaram forma na Lei 13425/2017. Do valor total, US\$ 221 milhões seriam direcionados para ao Programa para Resultados (PforR). Conforme a fala da secretária de Educação Básica do MEC, Rossieli Soares, este empréstimo seria para "apoiar a reforma do Ensino Médio, tendo como eixo a formação de professores das redes, a construção de currículos, além de estudos de viabilidade para o que fazer em cada uma das redes, respeitando o seu contexto local" (MINISTÉRIO DA EDUCAÇÃO, 2017). O restante do empréstimo, na ordem de
US\$ 21 milhões, seria destinado a consultorias contratadas pelo próprio Ministério da Educação. Ainda, o Banco Internacional para Reconstrução e Desenvolvimento (Bird), munido de indicadores, acompanharia a eficiência dos projetos financiados pelo dinheiro.

As parcerias entre o Banco Mundial e a reforma do Ensino Médio assinalavam-se desde a visita do ministro da Educação, Mendonça Filho, aos representantes do Banco Mundial, em março de 2017, em Washington (EUA). A submissão do governo brasileiro ao Banco Mundial cristaliza, portanto, esta articulação financeira com o Bird, o que, embora fira a soberania nacional, era esperado, uma vez que a referida reforma sustenta-se em orientações do Banco Mundial.

Observa-se que as matizes teóricas que fundamentam a Lei 13415/2017 são desterritorializadas e deslocadas sob a forma de uma nova diretriz pedagógica. Assim, o que se apresenta como novo na Lei $13415 / 2017$, na verdade é uma reciclagem da função dinamizadora do trabalho que historicamente estiveram a cargo da educação pública. Embora se propague que este seja um momento de rupturas com as diretrizes pedagógicas do passado, o que se tem observado são suas permanências revestidas de novas roupagens.

\section{CONSIDERAÇÕES FINAIS}

Procurou-se nesse trabalho proceder a uma reflexão acerca das contradições que estão postas na relação sujeito, trabalho, sociedade e educação que historicamente se fizeram presentes nos debates a respeito da educação pública em nível médio, no Brasil. Nesse viés, entende-se se que a Lei 13415/2017, intitulada pelo governo como reforma do Ensino Médio, exerce uma função importante na manutenção da condição de dependência e subordinação historicamente desempenhada pelo Brasil; reproduzindo um sistema econômico e político excludente, reforçando e naturalizando o lugar ocupado pelos países subdesenvolvidos no mercado mundial. Ao mesmo tempo, busca-se abrandar a pobreza absoluta e, assim, garantir a segurança do mundo do capital.

São questões que evidenciam a importância de se analisar as mútuas relações entre educação e trabalho em um contexto em que o pensamento educacional hegemônico aponta para reafirmação do saber como uma mercadoria desvinculada de seu caráter social e histórico; no qual a diferença entre inclusão e 
exclusão passa a ser concebida como níveis de eficiência da escola em aferir competências ao individuo para inserir-se no mundo produtivo.

\section{REFERÊNCIAS}

ALMEIDA, J. R. P. História de instrução pública no Brasil, 1500 a 1889. São Paulo: Educ.; Brasília: INEP-MEC, 1989.

ANDRADE, A. A. B. A reforma pombalina dos estudos secundários (1759-1771): contribuição para a história da pedagogia em Portugal. Coimbra: Universidade de Coimbra, 1984.

BACHA, E. L. Recessão ou crescimento: o FMI e o Banco Mundial na América Latina. Rio de Janeiro: Paz e Terra, 1986.

BANCO MUNDIAL. Prioridades y estratégias para la educacion. Washington, D.C.: World Bank, 1995.

BEISIEGEL, C. R. Estado e educação popular. São Paulo: Pioneira, 1974.

BRASIL. Congresso Nacional. Lei no 13415, de 16 de fevereiro de 2017. Altera as Leis $\mathrm{n}^{\text {os }}$ 9.394, de 20 de dezembro de 1996, que estabelece as diretrizes e bases da educação nacional, e 11.494, de 20 de junho 2007, que regulamenta o Fundo de Manutenção e Desenvolvimento da Educação Básica e de Valorização dos Profissionais da Educação, a Consolidação das Leis do Trabalho. Diário Oficial da União, Brasília, DF, 16 fev. 2017. Disponível em: http://www.planalto.gov.br/ccivil_03/_Ato20152018/2017/Lei/L13415.htm. Acesso em: 07. out. 2017.

BRASIL. Constituição (1934). Constituição da República Federativa do Brasil: Senado Federal, 1934. Disponível em: http://www.planalto.gov.br/ccivil_03/constituica o/constituicao34.htm> Acesso em 20 set. 2017.

BRASIL. Congresso Nacional. Lei no 16 de 12 de agosto de 1834. Faz algumas alterações à Constituição Politica do Imperio, nos termos da Lei de 12 de Outubro de 1832. Diário Oficial da União, Brasília, 21 ago. 1834. Disponível em: http://www.planalto.gov.br/ccivil_03/leis/LIM/LI M16.htm. Acesso em: 07 out. 2017.

BRASIL. Congresso Nacional. Lei no 4.024, de 20 de dezembro de 1961. Fixa as Diretrizes e Bases da Educação Nacional. Diário Oficial da União, Brasília, 20 dez. 1961. Disponível em: http://www.planalto.gov.br/CCIVIL_03/LEIS/L402 4.htm. Acesso em: 20 jan. 2013.

BRASIL. Congresso Nacional. Lei $n=5.692$, de 11 de agosto de 1971. Fixa Diretrizes e Bases para o ensino de $1^{\circ}$ e $2^{\circ}$ graus, e dá outras providências. Diário Oficial da União, Brasília, 11 ago. 1971. Disponível em:

http://www.planalto.gov.br/ccivil_03/LEIS/L5692 .htm. Acesso em 20 jan. 2013.

BRASIL. Ministério da Educação. Instituto Nacional de Estudos e Pesquisas Educacionais (INEP). Censo Escolar 2010. Brasília, 2010.

CARVALHO, J. M. A Construção da Ordem: a elite política imperial. Brasília: Ed. Universidade de Brasília, 1996.

DUARTE, N. O Construtivismo seria pós-moderno ou o pós-modernismo seria construtivista? In: DUARTE, N. Sobre o construtivismo: contribuições a uma análise crítica. Campinas: Autores Associados, 2005, p. 87-106.

FRIGOTTO, G. A produtividade da escola improdutiva. São Paulo, SP: Cortez, 2006.

HARVEY, D. 0 enigma do capital: e as crises do capitalismo. São Paulo: Boitempo, 2011.

MINISTÉRIO DA EDUCAÇÃO. Ministério da educação vai buscar apoio para implementação do novo Ensino Médio. 2017. Disponível em: http://portal.mec.gov.br/busca-geral/211noticias/218175739/51871-ministerio-vai-buscarapoio-para-implementar-novo-ensino-medio. Acesso em: 07 out. 2017.

PERONI, V. Política educacional e papel do Estado: no Brasil dos anos 1990. São Paulo, SP: Xamã, 2003.

PERRENOUD, P. A. Construir as competências desde a escola. Porto Alegre: Artmed, 1999.

PINTO, José Marcelino de Rezende. Os recursos para Educação no Brasil no contexto das finanças públicas. Brasília: Editora Plano, 2000.

RAMOS, M. A educação profissional pela pedagogia das competências e a superfície dos 
documentos oficiais. Campinas, Educ. Soc., v. 23, n. 80 , set. 2002, p. 401-422. https://doi.org/10.1590/S0101$\underline{73302002008000020}$

SAVIANI, D. A nova lei da educação: trajetória, limites e perspectivas. 4. ed. Campinas: Autores Associados, 1998.

TEIXEIRA, A. Educação no Brasil. 3. ed. Rio de Janeiro: UFRJ, 1999.

Recebido para publicação em: 05/10/2017

Revisado em: 06/11/2017

Aceito em: 13/11/2017 